\title{
CROSSROADS TO MORE POSITIVE ATTITUDES TOWARDS IMMIGRANTS: STUDENTS' EMPATHIC ABILITIES AND PERCEIVED CLASSROOM CLIMATE
}

\author{
Manja Veldin ${ }^{1}$, Ana Kozina ${ }^{1}$, Ana Mlekuž ${ }^{1}$, Tina Vršnik Perše ${ }^{1,2}$, Maša Vidmar ${ }^{1}$, \\ \& Urška Štremfel ${ }^{1}$ \\ ${ }^{I}$ Educational Research Institute (Slovenia) \\ ${ }^{2}$ Faculty of Education at University of Maribor (Slovenia)
}

\begin{abstract}
As important socialization agents, schools can provide an open climate as a contextual framework for the development of tolerant attitudes (Gniewosz \& Noack, 2008). Building positive attitudes towards immigrants can be addressed at the individual and school level. On an individual level, empathy is negatively connected to the development of prejudice (Miklikowska, 2018) and on the school level, classroom climate plays a role (Gniewosz \& Noack, 2008). On a class level, exposure to hate speech leads to desensitization and increasing prejudices (Soral, Bilewicz, \& Winiewski, 2018) whereas perceived equality and inclusion are positively associated with a sense of school belonging (Schachner, et al, 2018). The teachers are important as well, more specifically, students who perceive teachers as fair, report more tolerant views of immigrants (Gniewosz \& Noack, 2008). In the present study we have analysed the associations between students' attitudes towards immigrants with their empathic abilities, perceived relations with teachers and teachers' attitudes towards different cultural groups on a sample of 271 Slovenian $8^{\text {th }}$ grade students $(M=12,91, S D=0,44 ; 56,3 \%$ female) who participated in the European Erasmus KA3 + Hand in Hand project. We analysed the predictive power of empathy, perceived quality of student-teacher relations and inclusive classroom climate on students' attitudes towards immigrants. Results show that perspective taking and perceived teachers' attitudes towards different cultural groups are important predictors of students' attitudes towards immigrants. Results are discussed in light of guidelines for school practice.
\end{abstract}

Keywords: Attitudes towards immigrants, empathy, classroom climate, students.

\section{Introduction}

As important socialization agents, schools can provide an open climate as a contextual framework for the development of tolerant attitudes (Gniewosz \& Noack, 2008). Reducing prejudice and building positive attitudes towards outgroups, can be addressed on an individual and school level. On an individual level, empathy is negatively connected to the development of prejudice (Miklikowska, 2018) by enabling us to perceive similarities between ourselves and others (Davis, Conklin, Smith, \& Luce, 1996). On the school and class level, classroom climate influences on adolescents' attitudes towards immigrants (Gniewosz \& Noack, 2008), where exposure to hate speech leads to desensitization and increasing outgroup prejudices (Soral, Bilewicz, \& Winiewski, 2018). On the other hand, perceived equality, inclusion, and cultural pluralism are positively associated with a sense of school belonging (Schachner, Schwarzenthal, van de Vijver \& Noack, 2018) and students who perceive teachers as fair, report more tolerant views of immigrants (Gniewosz \& Noack, 2008). The present study aimed to analyse the associations between students' attitudes towards immigrants with their empathic abilities, perceived relations with teachers and teachers' attitudes towards different cultural groups.

\section{Method}

\subsection{Participants}

The randomized sample consisted of 271 Slovenian $8^{\text {th }}$-grade students from 12 primary schools ( $M=12,91$ years, $S D=0,44 ; 56,3 \%$ female) who participated in the European Erasmus KA3+ Hand in Hand project, which aimed to increase the social, emotional (e.g. self-awareness, self-management) and intercultural competencies of students and school staff. 


\subsection{Instruments}

Interpersonal Reactivity Index (IRI; Davis, 1980) was used as a measure of empathy. It consists of four scales; two of them labelled as emotional empathy (empathic concern, personal distress) and the other two as cognitive empathy (perspective taking, fantasy). In our study two scales (empathic concern and perspective taking) were included, where students assessed how well the items described them. Each had 7 items on a 5-point Likert scale (1 - "Not at all like me", 4 - "Very much like me"), Cronbach's alpha was .72 for perspective taking and .62 for empathic concern. Perceived quality of student-teacher relations (positive relations; Fischer et al., 2017; negative relations; OECD, 2018a) was used as a measure of classroom climate. In the positive relations, students assessed the number of teachers the statements apply to. It includes 8 items on a 4-point Likert scale (1 - "To none or almost none of them", 4 - "To all or almost all of them"), Cronbach's alpha was .87. The negative relations were assessed by the frequency of the negative experience between the teachers and students. It includes 7 items on a 4-point Likert scale (1 - "Never or almost never", 4 - "Every day or almost every day"). Cronbach's alpha was .77. Inclusive classroom climate (OECD, 2018b) measures student's perceived quality of student-teacher relations with a focus on teacher's sensitivity towards cultural and ethnic groups. Students assessed the number of teachers the statements apply to. The scale consists of 6 items on a 4-point Likert scale ( 1 - "To none or almost none of them", 4 - "To all or almost all of them"), Cronbach's alpha was .81. Attitudes Towards Immigrants (ATI; Schleicher \& Ramos, 2016) was used to evaluate student's attitudes towards people from different cultural background. The scale is comprised of 6 items, four original and additional two self-developed items. Students assessed their agreement with the statement on a 4-point Liker scale (1 - "Strongly disagree", 4 - "Strongly agree"), Cronbach's alpha was .71.

\subsection{Procedure}

In September 2018 students completed a paper version of questionnaires tapping SEI competencies, classroom climate, and demographic variables. We only present data for the selected measures. Reliability tests, descriptive statistics, correlations and hierarchical multiple regression analysis (method: Enter) were calculated with IBM SPSS Statistics 21.

\section{Results}

In Table 1, we can see all the correlations between the scales are significant. Attitudes towards immigrants have the largest positive correlation with inclusive classroom climate, where students assessed their teacher's sensitivity towards cultural and ethnic groups, followed by the perspective taking scale, while a significant negative correlation is found with the frequency of negative relations with teachers.

Table 1. Descriptive statistics and correlations between the scales.

\begin{tabular}{llllllll}
\hline Scale & $M$ & $S D$ & 1. & 2. & 3. & 4. & 5. \\
\hline 1. Empathic concern & 3,57 & 0,54 & & & & & \\
2. Perspective taking & 3,09 & 0,57 &, $48^{* *}$ & & & & \\
3. Quality of S-T relations (+) & 2,94 & 0,65 &, $27^{* *}$ &, $31^{* *}$ & & & \\
4. Quality of S-T relations (-) & 1,55 & 0,52 &,$- 13^{*}$ &,$- 18^{* *}$ &,$- 36^{* *}$ & & \\
5. Inclusive classroom climate & 3,46 & 0,52 &, $18^{* *}$ &, $13^{*}$ &, $25^{* *}$ &,$- 46^{* *}$ & \\
6. Attitudes towards immigrants & 2,90 & 0,48 &, $26^{* *}$ &, $28^{* *}$ &, $20^{* *}$ &,$- 26^{* *}$ &, $33^{* *}$ \\
\hline
\end{tabular}

Notes: $* * p \leq 0.01 ; * p \leq 0.05$. S-T=student-teacher

In Table 2, a hierarchical multiple linear regression is presented, with two empathy subscales (Step 1), quality of student-teacher relations (positive and negative; Step 2) and inclusive classroom climate (in form of intercultural attitudes of teachers; Step 3) included as predictors of attitudes towards immigrants. Empathy scales are important predictors of attitudes towards immigrants, they alone explain almost $10 \%$ of the variance. They also stay important positive predictors when adding quality of student-teacher relations into the regression model, whereas only the frequency of negative relations with teachers (and not positive) significantly predicts more negative attitudes of students. Model 2 explains $14 \%$ of the variance in attitudes towards immigrates. In the last step, when we add the students 'perceived intercultural attitudes of their teachers, as one of the inclusive classroom climate components, the frequency of the negative experiences loses its predictive significance. In Model 3, where all constructs are included, out of empathy subscales, only perspective taking is an important predictor while the teachers' intercultural attitudes add $4 \%$ to the explained variance of students' attitudes. When we only include these two into a regression, they alone explain $15,4 \%$ of the variance. 
Table 2. Hierarchical multiple regression analysis of variables that predict Attitudes towards immigrants.

\begin{tabular}{|c|c|c|c|c|c|c|}
\hline & \multicolumn{6}{|c|}{ Attitudes towards immigrants } \\
\hline & \multicolumn{2}{|c|}{ Model 1} & \multicolumn{2}{|c|}{ Model 2} & \multicolumn{2}{|c|}{ Model 3} \\
\hline & $B$ & $\beta$ & $B$ & $\beta$ & $B$ & $\beta$ \\
\hline \multicolumn{7}{|l|}{ Step 1: } \\
\hline Empathic concern & 0,15 & $0,17 *$ & 0,14 & $0,15 *$ & 0,11 & 0,13 \\
\hline Perspective taking & 0,16 & $0,19 * *$ & 0,13 & $0,15 *$ & 0,13 & $0,16 *$ \\
\hline$R^{2}$ & & $0,097 * * *$ & & & & \\
\hline \multicolumn{7}{|l|}{ Step 2: } \\
\hline Quality of S-T relations $(+)$ & & & 0,04 & 0,05 & 0,023 & 0,03 \\
\hline Quality of S-T relations (-) & & & $-0,19$ & $-0,20 * *$ & $-0,09$ & $-0,10$ \\
\hline$\Delta R^{2}$ & & & & $0,046 * *$ & & \\
\hline \multicolumn{7}{|l|}{ Step 3: } \\
\hline Inclusive classroom climate & & & & & & $0,23 *$ \\
\hline & & & & & 0,21 & \\
\hline$\Delta R^{2}$ & & & & & & $\begin{array}{r}\mathbf{0 , 0 3 9} \\
* *\end{array}$ \\
\hline$R^{2}$ & & $0,097^{* * *}$ & & $0,143^{* *}$ & & $0,182 * *$ \\
\hline$F$ for $\Delta R^{2}$ & & $14,14^{* * *}$ & & $10,86^{* * *}$ & & $1,50 * * *$ \\
\hline
\end{tabular}

\section{Conclusions}

Our study shows that on the individual level perspective taking, a cognitive component of empathy, representing the ability to see and understand the situation from the perspective of others, is an important predictor of attitudes towards immigrants. This is consistent with studies (Stephan \& Finlay, 1999) that show perspective taking is especially crucial when diminishing prejudices because it helps to acknowledge and understand diversities. At school or class level, our study shows inclusive climate is important, especially teachers' intercultural attitudes. Therefore, when trying to address the attitudes of students, the teacher's attitudes should also be considered. This supports the development of a programme, aiming at improving the empathic abilities of students (and teachers), especially focused on perspective taking. As the teachers' influence on the students is widely recognized, a whole-school approach should be considered, when creating an intervention.

\section{References}

Davis, M. H. (1980). A multidimensional approach to individual differences in empathy. JSAS Catalogue of Selected Documents in Psychology, 10, p. 85.

Davis, M. H., Conklin, L., Smith, A., \& Luce, C. (1996). Effect of perspective taking on the cognitive representation of persons: a merging of self and other. Journal of personality and social psychology, 70(4), 713.

Fischer, N., Decristan, J., Theis, D., Sauerwein, M. \& Wolgast, A. (2017). Skalendokumentation: Studie zur Entwicklung von Ganztagsschulen - Teilstudie StEG-S, In: Datenbank zur Qualität von Schule (DaQS), Frankfurt am Main.

Gniewosz, B., \& Noack, P. (2008). Classroom climate indicators and attitudes towards foreigners. Journal of adolescence, 31(5), 609-624.

Miklikowska, M. (2018). Empathy trumps prejudice: The longitudinal relation between empathy and anti-immigrant attitudes in adolescence. Developmental psychology, 54(4), 703.

OECD (2018a). PISA 2015 Technical Report. Paris: OECD

OECD (2018b). PISA 2018 Global Competence Questionnaire.

Schachner, M. K., Schwarzenthal, M., van de Vijver, F. J., \& Noack, P. (2018). How all students can belong and achieve: Effects of the cultural diversity climate amongst students of immigrant and nonimmigrant background in Germany. Journal of Educational Psychology.

Schleicher, A., \& Ramos, G. (2016). Global competency for an inclusive world. Organization for Economic Co-operation and Development (OECD). Organisation for Economic Co-operation and Development (OECD).

Soral, W., Bilewicz, M., \& Winiewski, M. (2018). Exposure to hate speech increases prejudice through desensitization. Aggressive behavior, 44(2), 136-146.

Stephan, W. G., \& Finlay, K. (1999). The role of empathy in improving intergroup relations. Journal of Social issues, 55(4), 729-743. 